www.jmscr.igmpublication.org

Impact Factor 5.84

Index Copernicus Value: 71.58

ISSN (e)-2347-176x ISSN (p) 2455-0450

crossref DOI: _https://dx.doi.org/10.18535/jmscr/v5i9.49

Journal Of Medical Science And Clinical Research

IGM Publication

An Official Publication of IGM Publication

\title{
Diagnostic Yield of Various Procedures in Lung Cancer
}

\author{
Authors \\ Dr Sushant Muley ${ }^{1}$, Dr Radha Munje ${ }^{2}$, Dr Sanjay Gour ${ }^{3}$, Dr Jitesh Atram ${ }^{4}$ \\ ${ }^{1,4}$ Assistant Professor, ${ }^{2}$ Professor, ${ }^{3}$ Associate Professor \\ Department of Pulmonary Medicine, Indira Gandhi Govt Medical College, Nagpur \\ Corresponding Author \\ Dr. Radha Munje \\ Email: radhamunje@yahoo.com
}

\begin{abstract}
Background: Lung cancer is the most common cause of cancer related death worldwide. Early diagnosis is critical for initiation of specific therapy.

Aim and Objective: To study yield of various procedures in diagnosis of lung cancer.

Material and Methods: This prospective observational study was carried out at a tertiary care centre between December 2010 to august 2012. Total 60 patients presenting with clinical and radiological features suggestive of lung malignancy were studied. sputum cytology were done in all patients. Fibreoptic bronchoscopy, CT guided FNAC, pleural fluid cytology and biopsy were done in patients as per indication by the site of lesion.
\end{abstract}

Results: Sputum cytology was positive in 5 (8.33\%) of patients. BAL cytology was positive in 31(58.49\%) patients. Bronchial brush and punch biopsy were positive in 15(60\%) and 7(63.63\%) patients respectively. CT/ USG guided biopsy yielded diagnosis in 32 out of 35 (94.23\%) patients. Pleural fluid aspiration and pleural biopsy yielded diagnosis in $46.66 \%$ and $73.33 \%$ patients respectively.

Conclusion: Bronchoscopy is useful tool for diagnosis of centrally located lung cancer while CT/USG guided lung biopsy is superior for peripherally located lung cancer. Pleural fluid biopsy is useful for diagnosis where pleural fluid cytology is negative for malignancy.

Key Words; Lung cancer, Fibreoptic bronchoscopy, pleural biopsy.

\section{Introduction}

Lung cancer is the most common cause of cancer related death worldwide. Lung cancer is usually at the advanced stage at first diagnosis. Lung cancer can grow for long time before any sign or symptoms appear. In India, lung malignancy accounted $6.9 \%$ of all new cancer cases and 9.3 $\%$ of all cancer related deaths in both males and females, it is the commonest cancer and cause of cancer related mortality in men, with the highest reported incidences from Mizoram in both males and females ${ }^{(2)}$ In the four cities of Maharashtra (Mumbai, Pune, Nagpur and Aurangabad) the absolute numbers of newly diagnosed lung cancer patient is expected to increase from 3170 to 4788

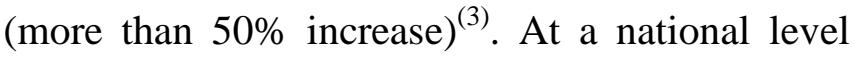
this would translate into 235,104 new patients. With $90 \%$ of these presenting in an advanced and inoperable stage, it would be challenging to diagnose this patients as early as possible. In this 
extremely challenging scenario we need to utilize all available modalities and advantages of technology that has the potential for early and accurate diagnosis so as to improve outcome in such patients. Lung masses have traditionally been evaluated through the use of planar chest X-rays, $\mathrm{CT}$ and MRI scanning. These tests can provide information regarding the size and location of the lung mass and only suggest the abnormality is benign or malignant with no absolute confirmation.

Unfortunately, the overall 5- year survival rate in patients with the different types of lung cancer is less than $10 \%$. However, that five-year survival rate can increase to $35-40 \%$ when lung cancer is diagnosed early enough to offer surgery before it has metastasized.

Most patients are between 55 to 65 years old when they are diagnosed with lung cancer and due to the state of their health or the location of the mass may not be good candidates for biopsy or other invasive procedures. Thus this study was undertaken to determine yield of various procedures in diagnosing lung cancer

\section{Materials and Method}

The study was conducted at a tertiary care centre between December 2010 and August 2012. All patients diagnosed with primary lung cancer were included in study. Written informed consent was taken from all patients prior to study. All demographic information, history, examination and laboratory details were noted for all patients. Routine blood investigations were done in all patients. Chest x ray, CT Thorax with upper abdominal cuts and USG abdomen were done in all patients. In cases of pleural effusion pleural fluid aspiration was done. Fluid was sent for biochemical and cytological examination. Pleural biopsy was also done in all cases of pleural effusion under all aseptic precautions and specimen was sent for histopathological examination in formalin bulb. Bronchoscopy was done in most of the cases except in cases with absolute contraindications for bronchoscopy.
Bronchial washings were taken in all cases. Bronchoscopic brush cytology, punch biopsy, TBNA, TBLB were done wherever applicable.

\section{Results}

Table-1: Sputum cytology

\begin{tabular}{|l|c|c|}
\hline Sputum cytology & No. of patients & Percentage \\
\hline Positive & 5 & $.33 \%$ \\
\hline Negative & 55 & $91.66 \%$ \\
\hline Total & 60 & $100 \%$ \\
\hline
\end{tabular}

Sputum cytology for malignant cells was positive in 5 out of 60 patients. In present study both induced sputum and post bronchoscopy sputum was sent for cytological examination. Post bronchoscopy sputum was positive for malignant cells in 3 patients. Out of 5 patients with positive sputum cytology, 3 patient were diagnosed with squamous cell carcinoma and 2 patients with adenocarcinoma.

Table-2: Bronchoscopic findings in cases of Lung Cancer

\begin{tabular}{|l|c|}
\hline Bronchoscopy Findings & No. of patients \\
\hline Normal & 8 \\
\hline Vocal cord palsy & 8 \\
\hline Tracheal external compression & 5 \\
\hline Widened main carina & 2 \\
\hline Bronchial external compression & 9 \\
\hline Endobronchial mass & 25 \\
\hline
\end{tabular}

Most common bronchoscopic abnormality was endobronchial mass found in 25 patients. Of 8 patients with vocal cord palsy 5 patients had left vocal cord palsy.

Table-3: Diagnostic yield of Bronchoscopic procedures in cases of Lung Cancer.

\begin{tabular}{|l|c|c|c|}
\hline Procedure & No. of patients & positive & Yield \\
\hline BAL cytology & 53 & 31 & $58.49 \%$ \\
\hline Bronchoscopic brushing & 25 & 15 & $60 \%$ \\
\hline Punch biopsy & 11 & 7 & $63.63 \%$ \\
\hline TBNA & 4 & 3 & $75 \%$ \\
\hline TBLB & 5 & 3 & $60 \%$ \\
\hline
\end{tabular}

In a present study, flexible fiberoptic bronchoscopy was done in 53 patients. Only bronchial washings were positive in 10 out of 53 patients (18.86\%). Bronchial washings and bronchial brush cytology combined were positive in 11 patients whereas bronchial washing and bronchoscopic punch biopsy combined was positive in 4 patients. 3 patients had positive 
findings on all three techniques viz. bronchial washings, bronchial brush cytology and punch biopsy. Punch biopsy was avoided in those patients who had bleeding on bronchoscopic brushing. TBNA was done in those patients who had subcarinal or mediastinal lymphadenopathy on CT thorax and tracheal or bronchial external compression on bronchoscpy findings.

Bronchial washings were positive in 9 out of 28 patients without endobronchial lesion (32.14\%). Bronchoscopy was diagnostic in 24 out of 25 patients with endobronchial lesion. Bronchoscopy was done twice in two patients to establish diagnosis of malignancy. Malignancies which are centrally located and presented with endobronchial lesion have better diagnostic yield as compared to those which are peripherally located or with no endobronchial presentation.

Table-4 : Diagnosis of peripherally situated lung cancer.

\begin{tabular}{|l|c|c|c|}
\hline Diagnostic procedure & $\begin{array}{c}\text { Number of } \\
\text { patients }\end{array}$ & $\begin{array}{c}\text { Positive } \\
\text { cytology }\end{array}$ & Yield (\%) \\
\hline Bronchoscopy & 28 & 9 & $32.14 \%$ \\
\hline CT/USGguided biopsy & 35 & 32 & $94.28 \%$ \\
\hline
\end{tabular}

By using Chi Square Test, $\mathrm{p}$ value $<0.001$. Thus CT/USG guided lung biopsy yielded significantly higher than bronchoscopy for diagnosis of peripheral lung cancer.

Table-5: Diagnostic yield of procedures in cases of pleural effusion.

\begin{tabular}{|l|c|c|c|}
\hline $\begin{array}{l}\text { Diagnostic } \\
\text { procedure }\end{array}$ & $\begin{array}{c}\text { Number of } \\
\text { patients }\end{array}$ & $\begin{array}{c}\text { Positive cytology/ } \\
\text { histopath }\end{array}$ & Yield (\%) \\
\hline $\begin{array}{l}\text { Pleural fluid } \\
\text { aspiration }\end{array}$ & 15 & 7 & $46.66 \%$ \\
\hline pleural biopsy & 15 & 11 & $73.33 \%$ \\
\hline
\end{tabular}

\section{Discussion}

The location, size and technique used in attempted bronchoscopic diagnosis of the lesions plays a significant role in the diagnostic yield. Lesion less than $2 \mathrm{~cm}$ have a diagnostic yield of $30 \%$, compared to $80 \%$ in those over $4 \mathrm{~cm}^{(4,5)}$. If a cytology brush is to be used to sample a peripheral lesion, it should be used before a transbronchial biopsy is performed, so as not to contaminate airway with blood that may later cover the brush $^{(5)}$. Some have suggested that bronchoalveolar lavage with 100-200 ml normal saline increases the yield of peripheral lesion when compared to brushings ${ }^{(6,7)}$. Baaklini and associates $^{(8)}$ found that by utilising flexible bronchoscopy, an overall diagnostic for peripheral malignant lesion could be obtained in 53\% however, when the size of lesion was less than 2 $\mathrm{cm}$ the diagnostic rate fell to $14 \%$ for outer one third lesions and $31 \%$ for those in the inner two third of the lung field. When utilising multiple diagnostic instruments during flexible bronchoscopy, Reichenberger and colleagues were able to obtain diagnosis of malignancy in $27.5 \%$ of patients with lesion less than $3 \mathrm{~cm}$ and in $65 \%$ of patients with lesion greater than $3 \mathrm{~cm}{ }^{(9)}$. In a study by Somnath Bhattacharya et al.(2012) diagnostic yield of pleural fluid cytology was $69 \%$ and diagnostic yield of blind pleural biopsy was $48 \%{ }^{(10)}$. In this study, out of 28 cases of peripheral tumours bronchoscopy diagnosed only 8 cases with a yield of $32.14 \%$, while CT/USG guided FNAB diagnosed 32 of 35 cases with a yield of 94.28\%. A study by Jagdish Ravat et al. Uttarakhand showed FNAB done under CT is the investigation of choice for peripherally situated lesions ${ }^{(11)}$.

\section{Conclusion}

The diagnostic yield of fibreoptic bronchoscopy is enhanced by different bronchoscopy techniques used simultaneously. Malignancies which are centrally located and presented with endobronchial lesion have better diagnostic yield as compared to those which are peripherally located or with no endobronchial presentation. Pleural biopsy is diagnostic in cases where pleural fluid cytology is negative for malignancy.

\section{References}

1. Liesbet Schrevens, Natalie Lorent, et al. The Role of PET Scan in Diagnosis, Staging and Management of Non-Small Cell Lung Cancer.The Oncologist 2004;9:633- 643 
2. National Cancer Registry Programme. Three Year Report of Population Based Cancer Registries: 2009-2011. Indian Council of Medical Research; 2013. Available from: http:// www.ncrpindia.org

3. Availablefrom:http://www.indiancancerso ciety.org/cancer-registry/ cancer-registry.aspx.

4. Zavala DC. Diagnostic Fibreoptic Bronchoscopy: techniques and results in 600 patients. Chest 1975;68:12.

5. Radke JR, Conway WA, Eyler WR, Kvale PA. Diagnostic accuracy with peripheral lung lesion: factors producing success with fibreoptic bronchoscopy. Chest 1979;76:176-179.

6. Pyrozynski M, Bronchoalveolar lavage in the diagnosis of peripheral primary lung cancer. Chest 1992;102: 372-374.

7. Shiner RJ, Rosenman J , Katz L. Bronchoscopic evaluation of peripheral lung tumours. Thorax 1988;43:887-889.

8. Baaklini WA, Reinoso MA, Gorin AB et al. Diagnostic yield of fiberoptic bronchoscopy in evaluating solitary pulmonary nodules. Chest 2000;114(4):1049-1054

9. Reicherberger F, Wever J, Tamm M. The value of transbronchial needle aspiration in the diagnosis of peripheral pulmonary lesions. Chest 1999;116(3):704-706.

10. Somnath Bhattacharya, Tapan D Bairagya, Anirban Das, Abhijit Mandal, Sibes K Das. Closed pleural biopsy is still useful in the evaluation of malignant pleural effusion. Journal of laboratory physician 2012; 4 (1):35-38

11. Jagdish Rawat, Girish Sindhwani, Dushyant Gaur, Ruchi Dua, Sunil Saini. Clinico-pathological profile of lung cancer in Uttarakhand Lung India 2009; 26(3):7476. 